\title{
A COMPARATIVE STUDY OF TWO BULLETIN CONTENTS OF AGRICULTURAL EXTENSION AND RURAL COMMUNITY RESEARCH
}

(Received: 29. 9. 2014)

\author{
U. Bdair and M. E. A. Abdel-Whab* \\ Agricultural Extension and Rural Development Research Institute, Agriculture Research Center, Giza \\ *Rural Sociology and Agricultural Extension Department, Faculty of Agriculture, \\ Cairo University, Giza, Egypt
}

\begin{abstract}
The objectives of the present study were to determine the proportion of the Agricultural Social Science Research (ASSR) compared to other disciplines published in the Bulletin of the Faculty of Agriculture, Cairo University (BFACU) and The bulletin of the Egyptian Journal of Agricultural Research Center (BEJARC) and to identify the research areas of agricultural extension and rural community in the two studied bulletins and to determine the level of participation in the ASSR published in the two studied bulletins, as well as to identify significant differences between the total degrees of overall participation of the ASSR published in the two studied bulletins.

The study samples included the ASSR published in BFACU and BEJARC during 3 years: 2011, 2012, and 2013. Data were collected and classified by content analysis from each research, as a single unit. Frequencies, percentages, mean, minimum, maximum, and "t" test were used to analyze the data.

The most important results were as follow:

1. The total number of ASSR published in BFACU and BEJARC were 9 and 26 representing $6.3 \%$ and $7.6 \%$ of the total published research papers in the two bulletins respectively.

2. The number of agricultural extension and rural community research areas covered by BFACU were three only for each specialization from the seven areas, compared with five areas covered for each specialization in BFACU and BEJARC.

3. The majority of the ASSR published in BEJARC fall in the medium and low participation categories with percentages $55.6 \%$ and $44.4 \%$, respectively, as well as in the BEJARC. The majority of the ASSR fall in the low and medium participation categories with percentages $73.1 \%$ and $26.9 \%$, respectively. While there was no research of ASSR published in the high participation category of both bulletins.

4. No significant difference was found between the means of participation scores in the two bulletins.
\end{abstract}

Key words: agricultural extension, interdisciplinary and multidisciplinary research, rural community.

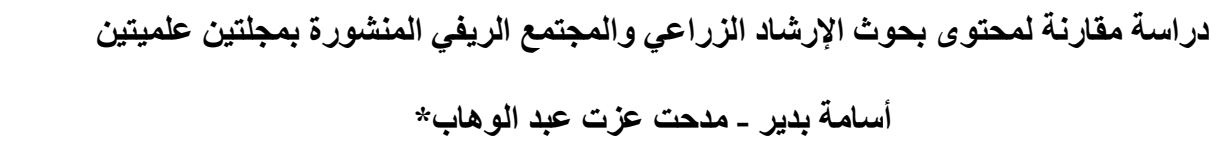

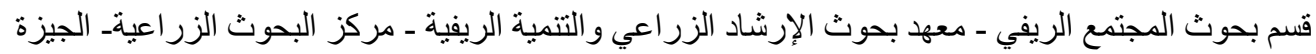

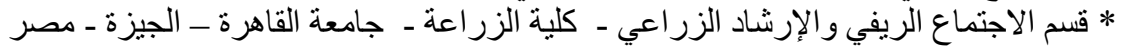

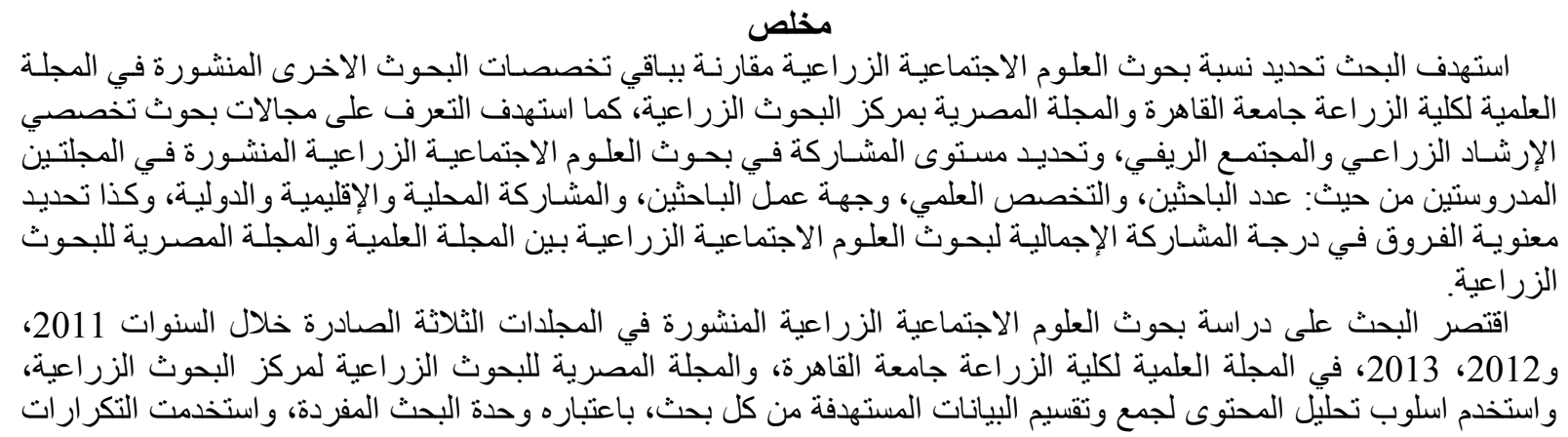


و النسب المئوية لعرض النتائج، بالإضافة إلى المدى وأكبر قيمة وأقل قيمة لتقسيم متغير المشاركة الى فئات، كما استخدم المنوسط الحسابي واختبار "t" لتحديد معنوية الفروق بين اللفين المتوسطات.

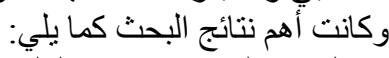

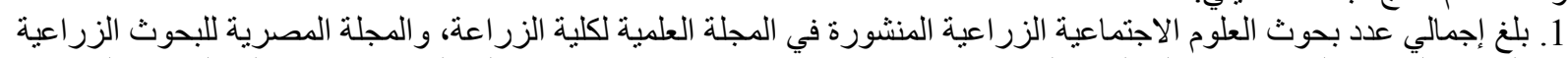

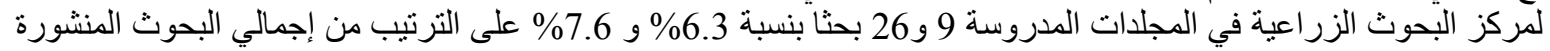
بالمجلتين. 2. لوحظ أن عدد المجالات التي شملتها بحوث الإرشاد الزراعي والمجتمع الريفي المنشورة في المجلة العلمية ثلاثة فقط لكل تخصص

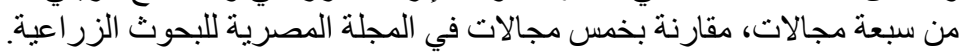

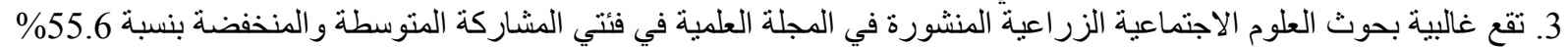

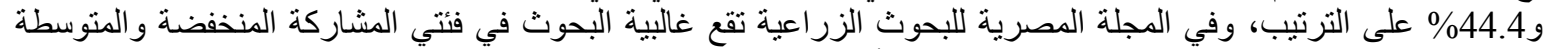

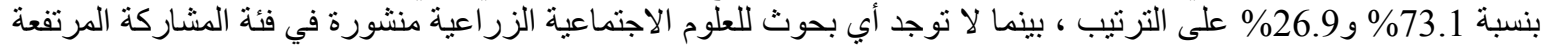
لكتا المجلتين المدروستين. 4. عدم وجود فروق معنوية في درجة المشاركة الإجمالية لبحوث العلوم الاجتماعية الزراعية بين المجلة العلمية والمجلة المصرية اللبحوث الزر اعية.

مبهرة في زيادة الانتاجية الزر اعيـة من الوحدة الأرضية لكثير

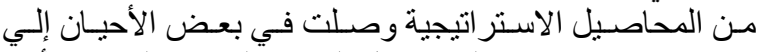

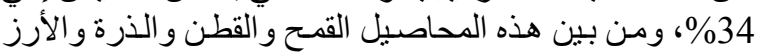
و الفول وغير ها. ويذكر بدير (2014) أنه لما كان العامل الإنساني هو محور

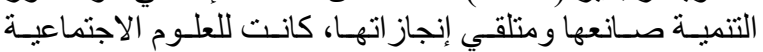

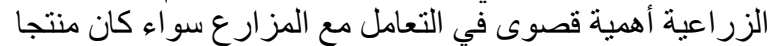

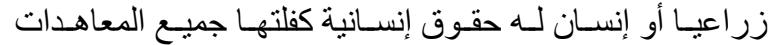

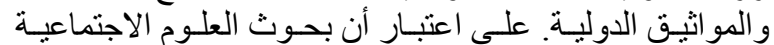

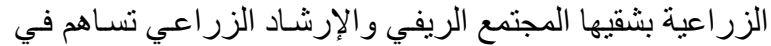

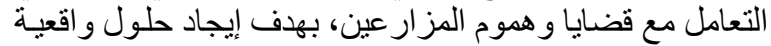

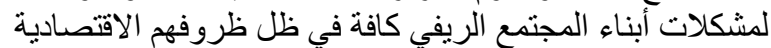

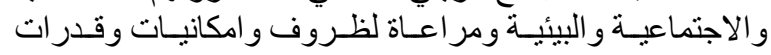

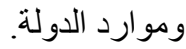

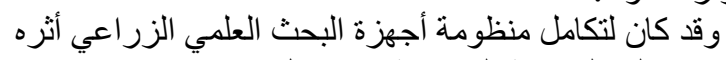

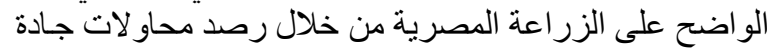

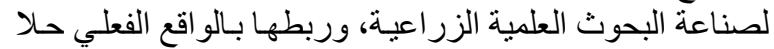

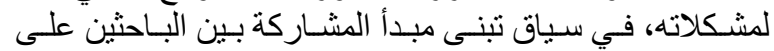

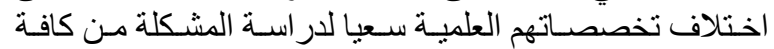

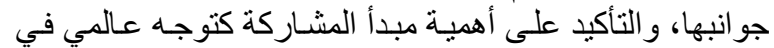

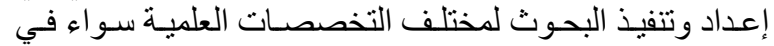

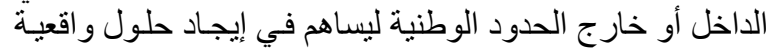

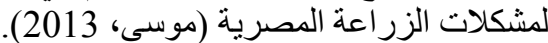

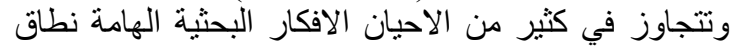

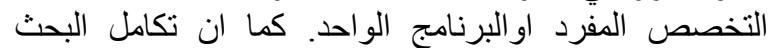

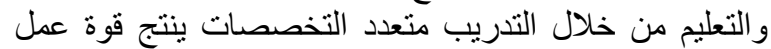

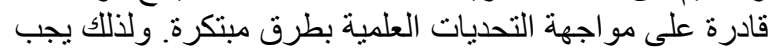

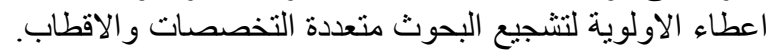

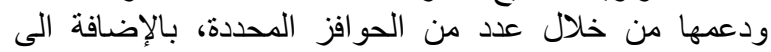

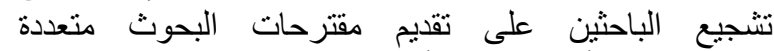

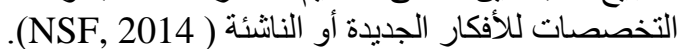

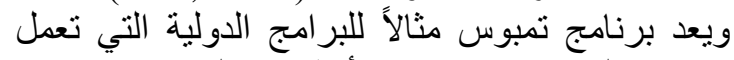

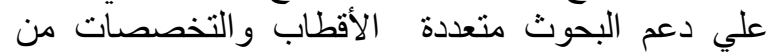
خلال تشجيع التعاون بين المؤستودة الأطسات العلمية الاكاديمية

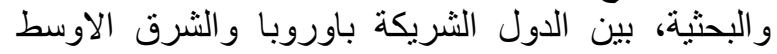

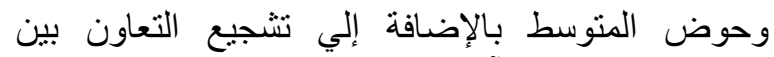

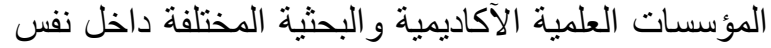

$$
\text { الدولة ( برنامج تمبوس، 2010). }
$$

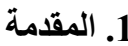

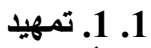

أصبحت الحاجة إلى البحث العلمي في وقتنـا الحاضر أثند

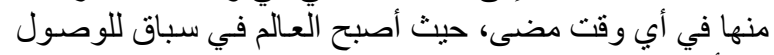

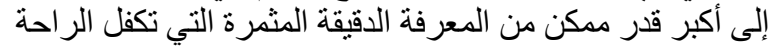

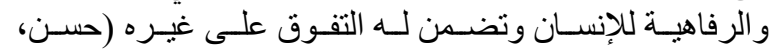

(2012)

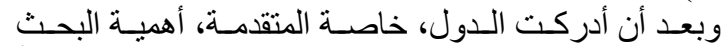

العلمي و عظم الدور الذي يؤديه في التقدم و التنمية، أولتهه كثبراً

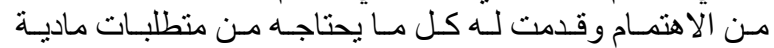

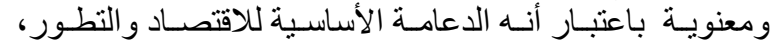

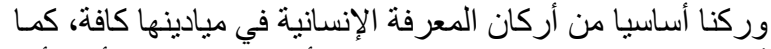

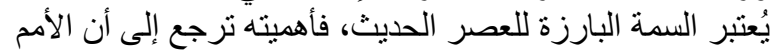

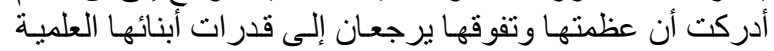
و الفكرية و السلوكية (منصور ، 2010 2013).

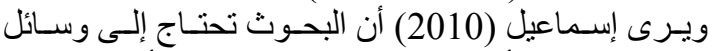

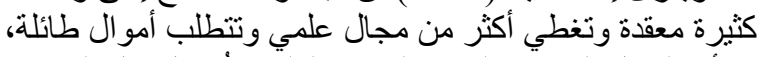

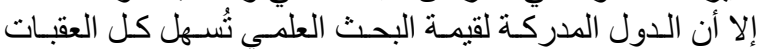

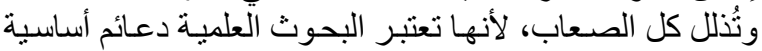

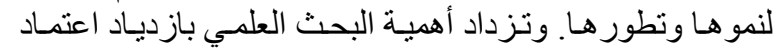

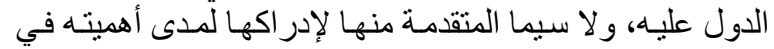

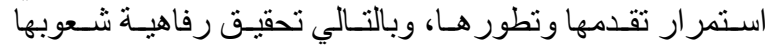
و المحافظة على مكانتها.

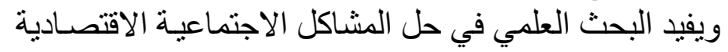

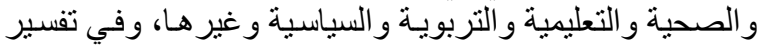
الظواهر الطبيعية والتتبؤ بها عن طريق التئية الوصول إلى تعيميات

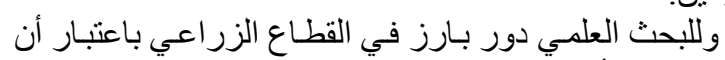

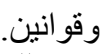

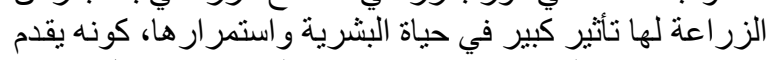

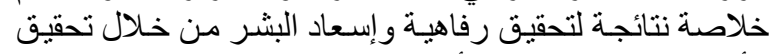

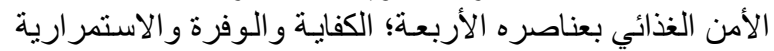

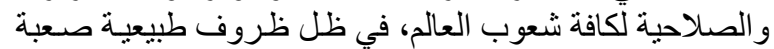

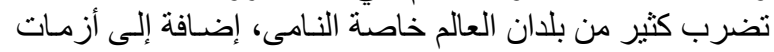

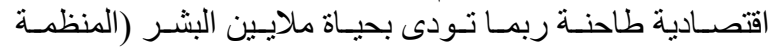
العربية للتنمية الزر اعية، 2010).

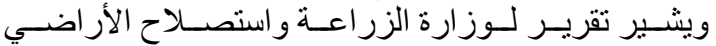

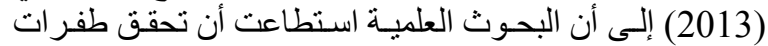

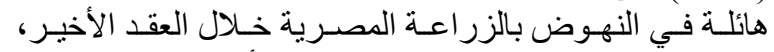

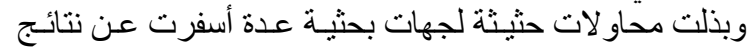




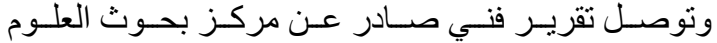

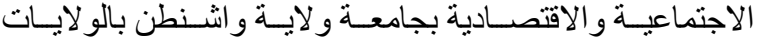

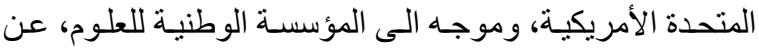

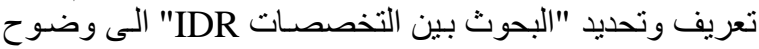

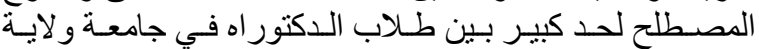

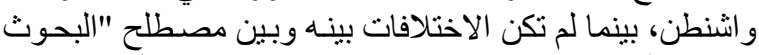

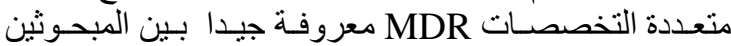

(Millar and Dillman, 2010 )

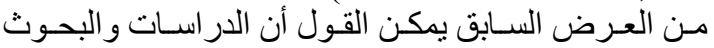

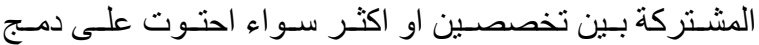

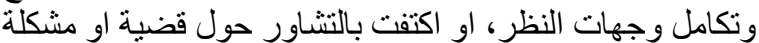

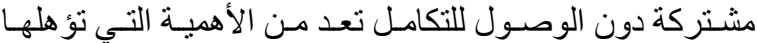

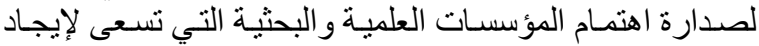
حلول و اقعية تساهم في حل كثير من المشكلات

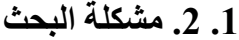

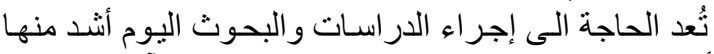

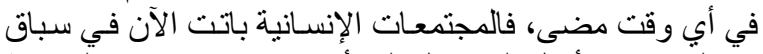

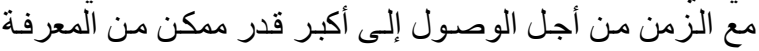

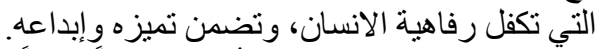

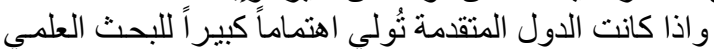

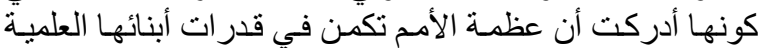

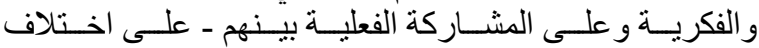

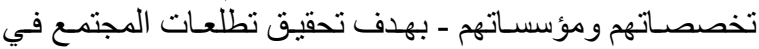

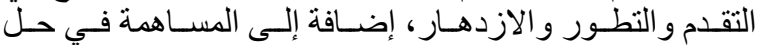

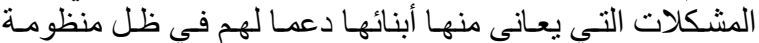

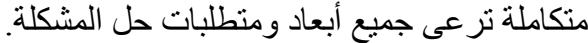

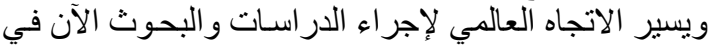

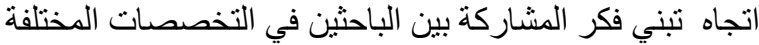

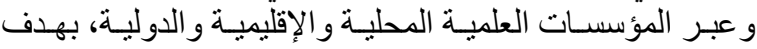

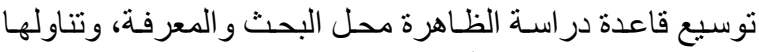

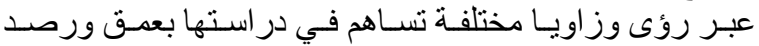

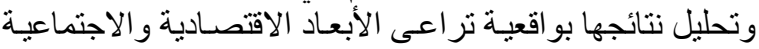
و البيئية و الجيوسياسية للمجتمع (بوبر، 2009).

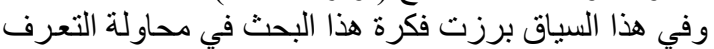

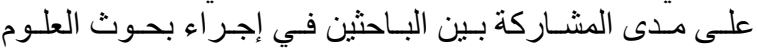

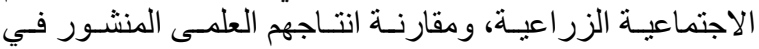

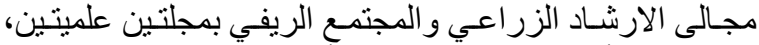

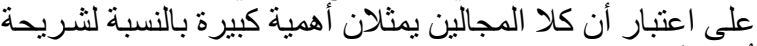

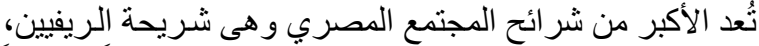

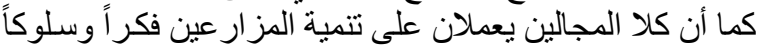

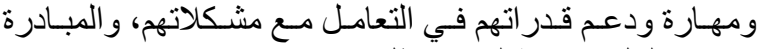

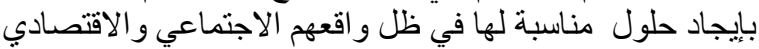

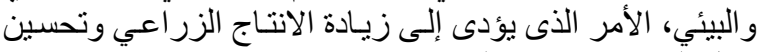

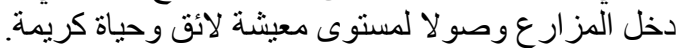

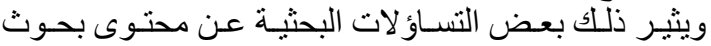

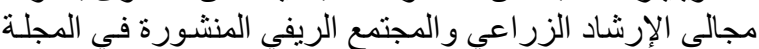

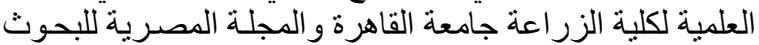

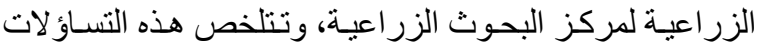

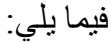

1. 2. 1. مـا نسبة بحـوث العلوم الاجتماعيـة الزر اعبـة مقارنــة

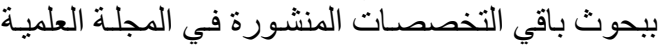

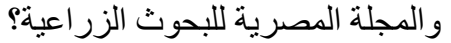

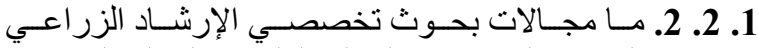
و المجتمع الريفي في المجلة العلمية و المجلة المصرية الزراعية

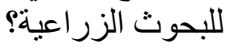

ورغم كل الجهود التي بذلت، وما زالت تبذل سعيا لتأصيل

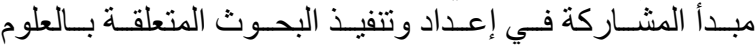

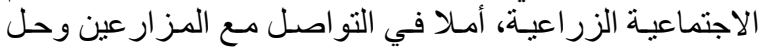

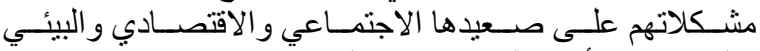
و الخدمي، إلا أن هناك حزمة من المعوقات التات تقف عثرة في طريق الإيق

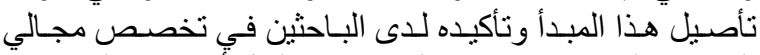

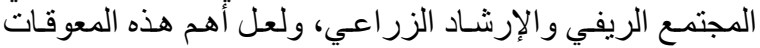

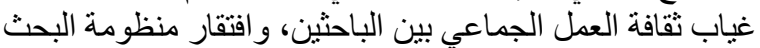

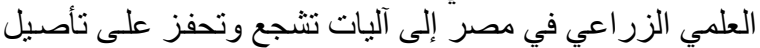

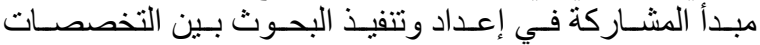
و المؤسسات البحثية المختلفة في داخل أو خارج الحثرة الحدود الوطنية.

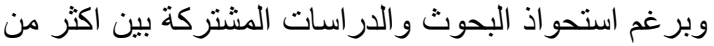

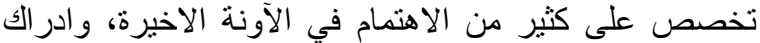

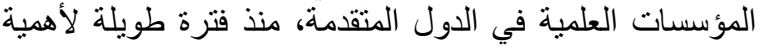

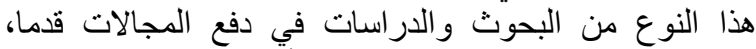

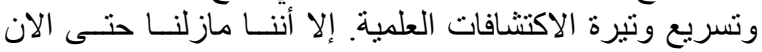

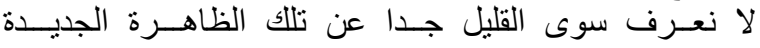

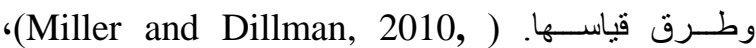

.(NSF,2014)

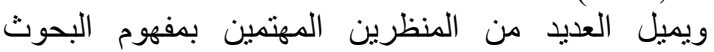
المشتركة بين اكثر من تخصص علدي التئرين استخدام مصطلح "البحوث بين التخصصات Interdisciplinary research (IDR)

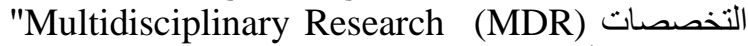
للإنشارة الى أب بحث من هذه النوع. في حين لم بستخدم العديد

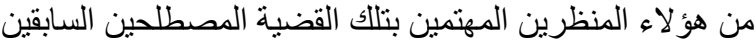

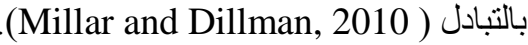

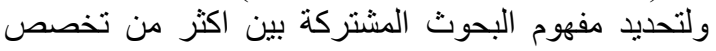

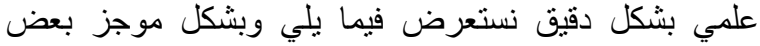
الدفاهيم و الدصطلحات ذات دئ العلاقة: هناك تعاريف متعددة لمصطلح "البحات العوثة بين التخصصات

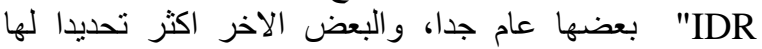

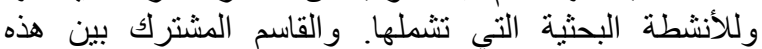

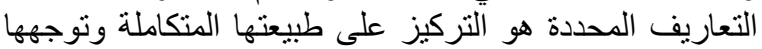

في حل المشكلات. (Millar and Dillman, 2010).

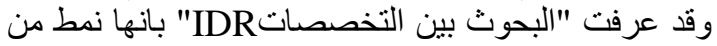

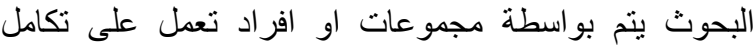

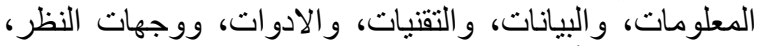

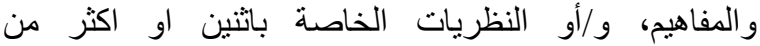

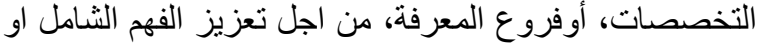

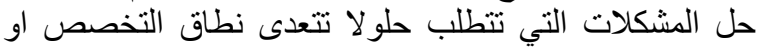

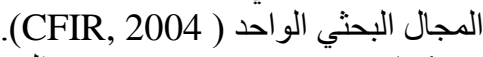
كما عرف (Repko, 2012) "الدراسات بين التخصصات

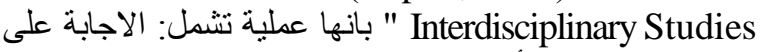

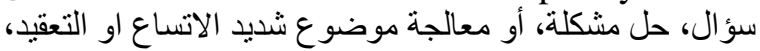

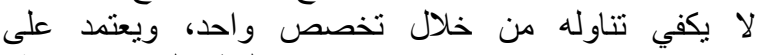
تخصصات عديدة بهدف دمج وجهات النظر لبناء فهم اكثر

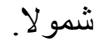

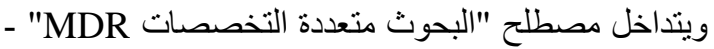

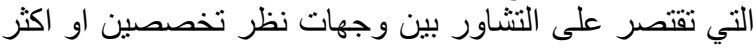
لمشكلة مشتركة دون حدوث التكامل بينهما - مع مصطئح

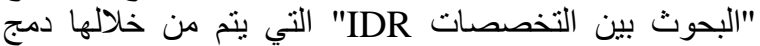
وتكامل وجهات نظر تخصصين او التهر الثر حول مشكلة مشتركة بينهم لبناء فهم اكثر عمقاوشمولا ( Repko, 2012 (يطرل 


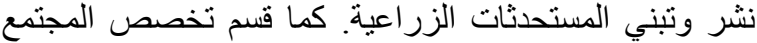

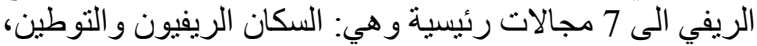

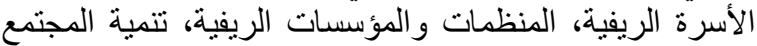

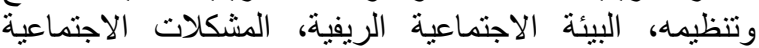

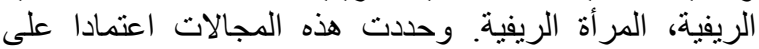

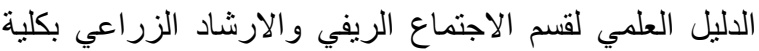

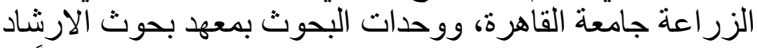

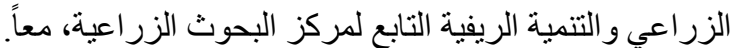

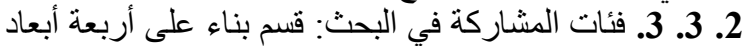

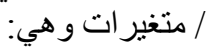

2. 3. 1. 1. فئات عدد الباحثين، وقسمت إلى رئ: فردي، زوجي،

$$
\text { ثلاثي، رباعي. }
$$

2. 3. 3. 2. جهة العمل، وقسمت باعث إلى: الجامعات، المر اكز البحثية، مشترك اك بين الجهتين.

2. 3. 3. 3. الدولة، وقسمت إلى: مصر (المحلية)، الدول العربية، الدول الاجنبية ، مشترك بين أكثر من دولة.

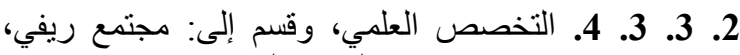
إرشاد زر اعي، مشترك بين التخصي وفصين.

2. 2. 4. 1التعاريف الاجرائية

2. 1. 1. 4حوث العارئو الاجرائة الاجتماعية الزراعية: يقصد بها هنا بحوث تخصصي الإرشاد الزر اعي و المجتمع الريفة الزيفي.

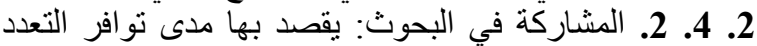

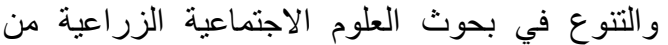

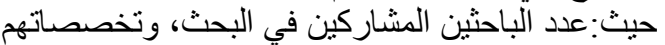

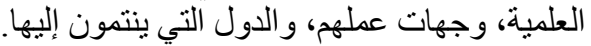
2. 5. 5. القياس الكمي لمتغير المشاركة في البحوث البهاث

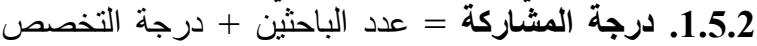

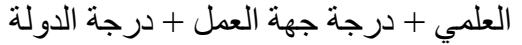
2.5.2. عد "الباحثين: أعطيث درجة وداحدة للبحث الفردي،

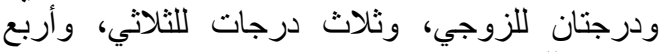
درجات للرباعي.

3.5.2. درجة التخصص العلمي: أعطيت درجة واحدة إذا كان

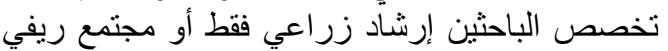

$$
\text { فقط، ودرجتين للمشترك البين بينهما. }
$$

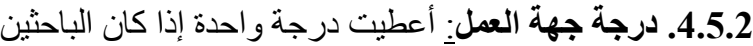

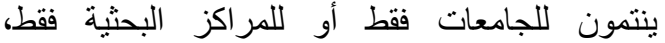

ودرجتين للمشترك بينهما.

5.5.2. درجة الدولة: أعطيت درجة واحدة إذبنة إذا كان الباحثين

ينتمون لمصر فقط أو لاولة الدوبة عربية فقط أو لدولة ألة أجنبية

فقط ودرجتين للمشترك بين أكثر من دولة لـنة

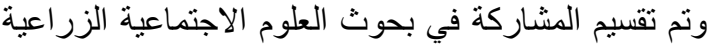

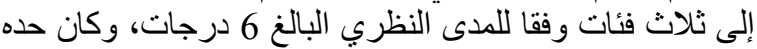

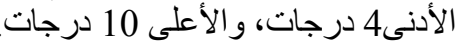
2. 6. التحليل الاحصائي

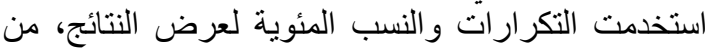

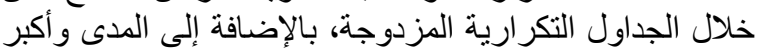

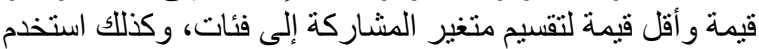
المتوسط الحسابي واختبار "t" لتحديد معنوية الفروق بين لفين المتوسطات.

\section{3. التتائج والمناقشة الإئشة}

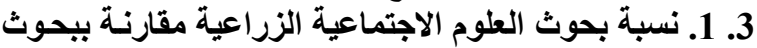
باقي التخصصات بالمجلتين المدروستين

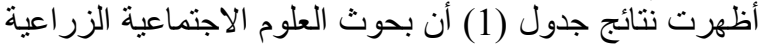
المنشورة سنة 2011 في المجلة العلمية بلغ 7 بحوث الاعن بنسبة
1. 2. 3. مـا مسـتوى المشـاركة في بحسوث العلـوم الاجتماعيـة

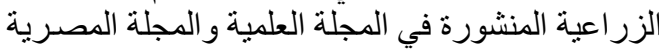

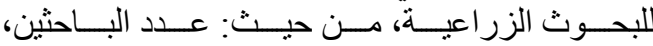

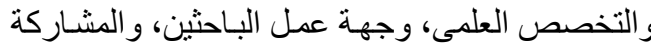
المحلية و الإقليمية و الدولية؟ والئه

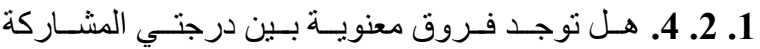

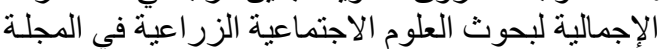

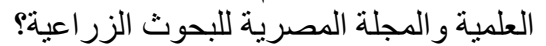

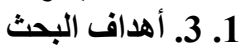

في ضوء العرض السابق لمشكلة البحث تحددت أهدافه فيما يلى:

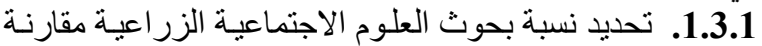

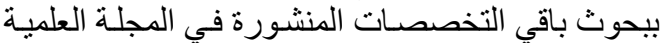
و المجلة المصرية للبحوث الزئ الزر اعية.

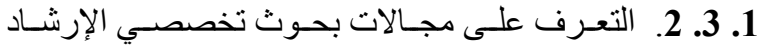

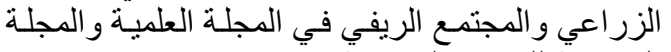
المصرية للبحوث الزر اعية.

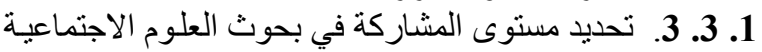

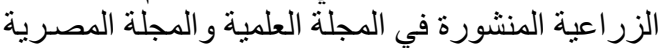

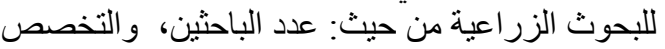

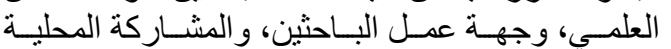
و الإقليمية و الدولية.

1. 3. 4. تحديد معنويـة الفروق في درجة الإلة المثـاركة الإجماليـة

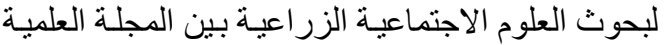

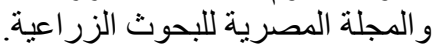
1. 4. الفرض الإحصائي

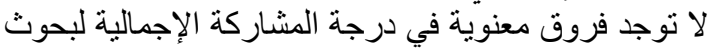

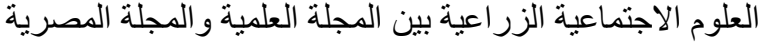
للبحوث الزرم الاجية اعية الزية

2. الطريقة البحثية

2. 1. شاملة وعينة البحث

تتكون شاملة البحث من بحوث البئة العلوم الاجتماعية الزر اعية

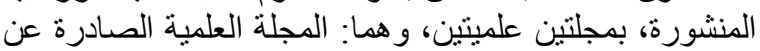

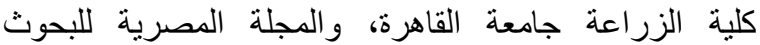

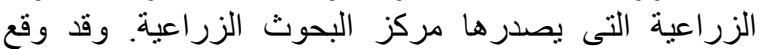

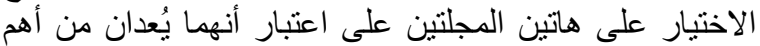

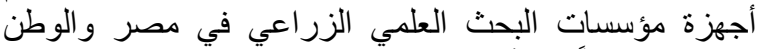

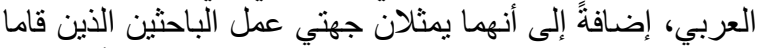
بإعداد البحث، فكلية الزراعة تمثل مؤسسة تعليمية أكاديمية،

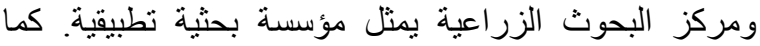

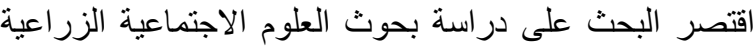

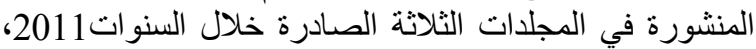

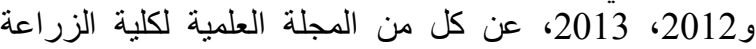

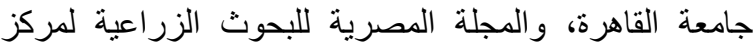
البحوث الزر اعية والتي يشمل كل منها أربعة أعداد. 2. 2. 2. طريقة جمع البياتنات

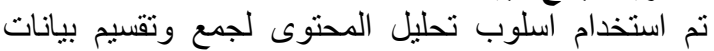
البحث، و أخضع كل بحث للتحليل كوحدة مفردة.

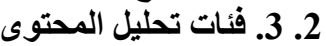

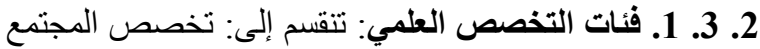

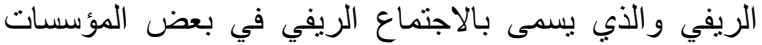

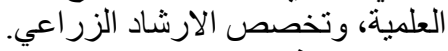

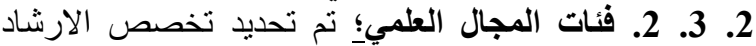

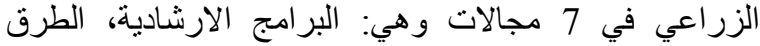

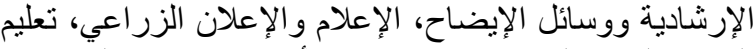

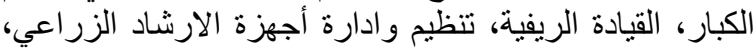


جدول (1): نسبة بحوث العلوم الاجتماعية الزراعية مقارنة بباقي التخصصات بالمجلتين المدروستين.

\begin{tabular}{|c|c|c|c|c|c|c|c|c|c|}
\hline \multirow{2}{*}{\multicolumn{2}{|c|}{ المجموع }} & \multicolumn{6}{|c|}{ سنوات المجلتين المدروستين } & \multirow{3}{*}{ التخصصات العلمية } & \multirow{3}{*}{ أسم المجلة } \\
\hline & & \multicolumn{2}{|c|}{2013} & \multicolumn{2}{|c|}{2012} & \multicolumn{2}{|c|}{2011} & & \\
\hline$\%$ & العدد & $\%$ & العدد & $\%$ & العدد & $\%$ & العدد & & \\
\hline 6.3 & 9 & 4.3 & 2 & 0 & 0 & 14.3 & 7 & العلوم الاجتماعية الزر اعية & ة \\
\hline 93.7 & 134 & 95.7 & 44 & 100.0 & 48 & 85.7 & 42 & التخصصات الاخرى & 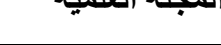 \\
\hline 100.0 & 143 & 100.0 & 46 & 100.0 & 48 & 100.0 & 49 & & المجموع \\
\hline 7.6 & 26 & 8.1 & 9 & 10.8 & 13 & 3.6 & 4 & العلوم الاجتماعية الزر اعية & المحلة المصرية \\
\hline 92.4 & 316 & 91.9 & 102 & 89.2 & 107 & 96.4 & 107 & التخصصات الاخرى & لبحوث الزراعية \\
\hline 100.0 & 342 & 100.0 & 111 & 100.0 & 120 & 100.0 & 111 & & المجموع \\
\hline
\end{tabular}

هيئة التدريس بكلية الزراعة جامعة القاهرة التى تصدر المجلة العلمية. 3. 2. مجالات بحوث تخصصى الإرشاد الزراعي والمجتمع المدرئ الريفي بالمجلتين المدروستين

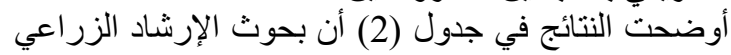

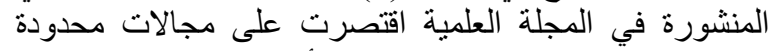

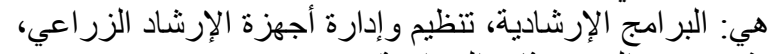

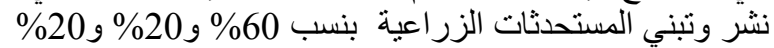
على الترتيب من إجمالى بحوث الإرشاد الزراعي المنشورة

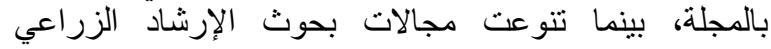

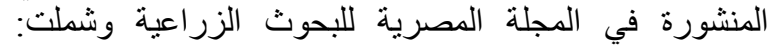

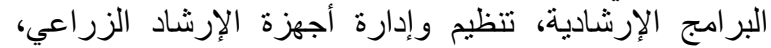

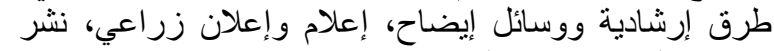

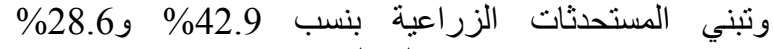

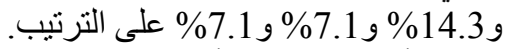

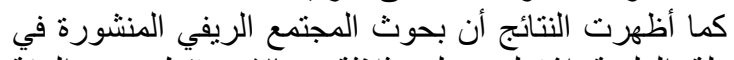

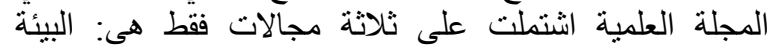
الاجتماعية الريفية، تتمية المجتمع وتتظيمهاه، الأسرة الريفية
14.3\% من إجمالي كل البحوث، في حين بلغ عددها في المجلة

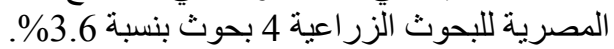

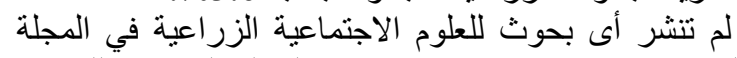

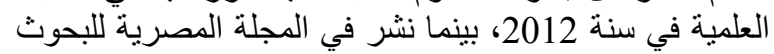
الزر اعية 13 بحثا بنسبة 10.8\% من إجمالي البحوث المنشورة في المجلة. نشر في المجلة العلمية بحثنان في العلوم الاجتماعية

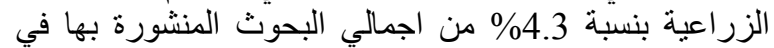
سنة 2013، في حين بلغ عدد البحوث النئ المنشورة في المجلة

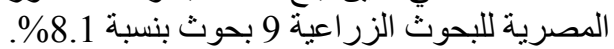

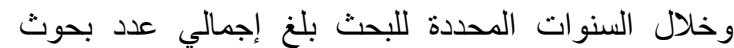

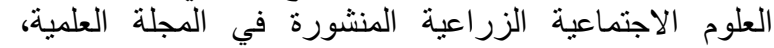

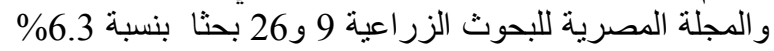
و 7.6\% على الترنتب من إجمالي البحوث المنشورة بالمجلتين.

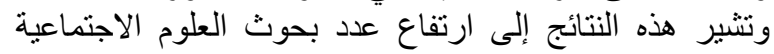

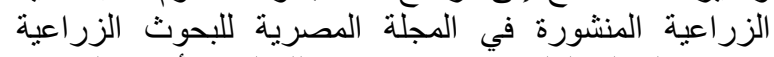

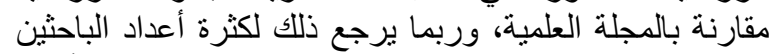
في مركز البحوث الزراعية الذى يصدر المجلة مقارنة بأعداد

\begin{tabular}{|c|c|c|c|c|c|}
\hline \multicolumn{2}{|c|}{ المجلة المصرية للبحوث الزراعية } & \multicolumn{2}{|c|}{ المجلة العلمية } & \multirow{2}{*}{ المجالات الرئيسية } & \multirow{2}{*}{ التخصص } \\
\hline$\%$ & العدد & $\%$ & 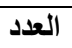 & & \\
\hline 42.9 & 6 & 60.0 & 3 & البر امج الارشادية & \multirow{7}{*}{ الارشاد الزراعي } \\
\hline 14.3 & 2 & 0 & 0 & طرق ارشادية ووسائل ايضاح & \\
\hline 7.1 & 1 & 0 & 0 & اعلام و اعلان زراعي & \\
\hline 0 & 0 & 0 & 0 & تعليم كبار & \\
\hline 0 & 0 & 0 & 0 & قيادة ريفية & \\
\hline 28.6 & 4 & 20.0 & 1 & 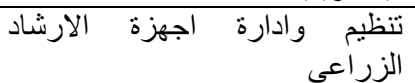 & \\
\hline 7.1 & 1 & 20.0 & 1 & نشر وتبني المستحدثات الزر اعية & \\
\hline 100.0 & 14 & 100.0 & 5 & & المجموع \\
\hline $\mathbf{0}$ & $\mathbf{0}$ & $\mathbf{0}$ & $\mathbf{0}$ & السكان الريفيين و التوطين & \multirow{7}{*}{ المجتمع الريفي } \\
\hline 8.3 & 1 & 25.0 & 1 & الاسرة الريفية & \\
\hline 25.0 & 3 & $\mathbf{0}$ & $\mathbf{0}$ & المنظمات و المؤسسات الريفية & \\
\hline $\mathbf{0}$ & $\mathbf{0}$ & 25.0 & 1 & تتمية المجتمع وتنظيمه & \\
\hline 33.3 & 4 & 50.0 & 2 & البيئة الاجتماعية الريفية & \\
\hline 8.3 & 1 & $\mathbf{0}$ & $\mathbf{0}$ & المشكلات الاجتماعية الريفية & \\
\hline 25.0 & 3 & $\mathbf{0}$ & $\mathbf{0}$ & المر اة الريفية & \\
\hline 100 & 12 & 100.0 & 4 & & المجموع \\
\hline 100.0 & 26 & 100.0 & 9 & & الاجمالي \\
\hline
\end{tabular}


إجمالي البحوث المنشورة، بينما كان أكبر عدد للمشاركين في المئ

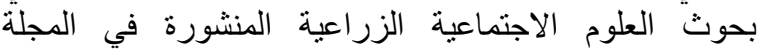
المصرية للبحوث الزراعية بشكل فردى بواقع 14 بحثا بنسبة الرية $\% 53.8$

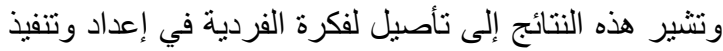

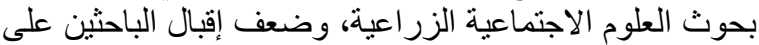

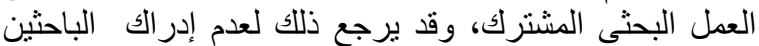

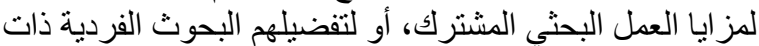

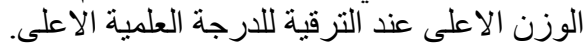
3. 3. 2. التخصص التص عند أوضحت نتائج جدول (4) أن بحوث المجتمع الريفي

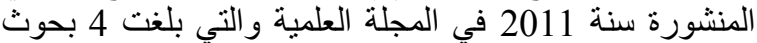

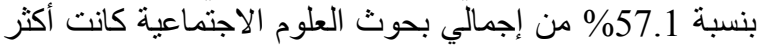

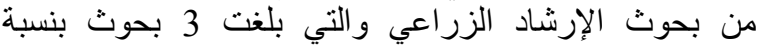

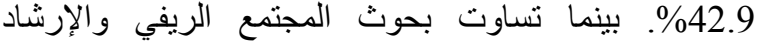

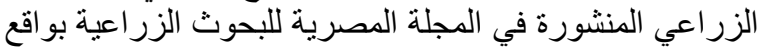

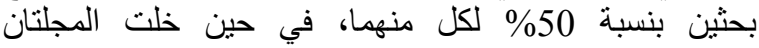
الدروستان من بحوث العلوم الاجتماعية الزراعية ذات ذات التخصص المشترك. ولم تتشر أى بحوث للعلوم الاجتماعية الزراعية في المجلة

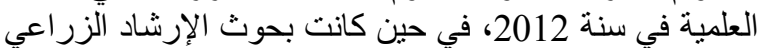

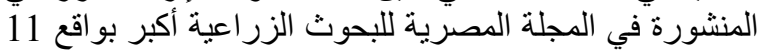

بنسب 50\% و25\% و25\% على الترتيب من إجمالى بحوث المجتمع الريفي المنشورة بالمجلة، في حين بلغت الغت مجالات الهيت بحوث المجتمع الريفي المنشورة في المجلة المصرية للإيحوث

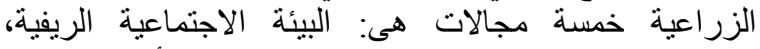
المنظمات والمؤسسات الريفية، المراة الرئية الريفية، الأسرة الريفية، الرئة

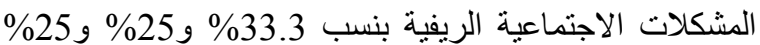
و8.3 \% و 8.3\% على الترتيب. وقد يعزى تفسير هذه النتائج إلى أن الباحثين المشاركين في الإي

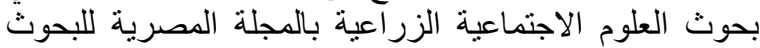

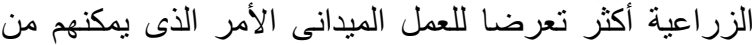
تاول مجالات بحثية متنو عة.

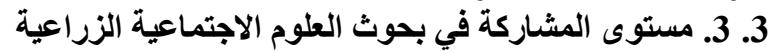

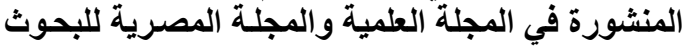

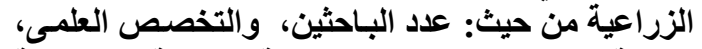

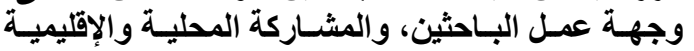

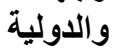

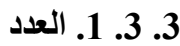
أثنارت النتائج في جدول (3) إلى أن أكبر عدد للمشاركين

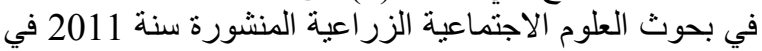

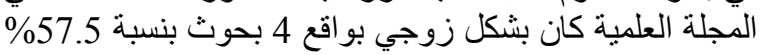

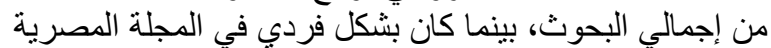

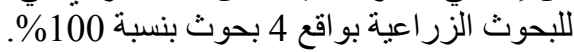

جدول (3): مقارنة بين المشاركين في بحوث العلوم الاجتماعية الزراعية المنشورة بالمجلتين المدروستين من حيث العدد.

\begin{tabular}{|c|c|c|c|c|c|c|c|c|c|}
\hline \multicolumn{2}{|c|}{ المجموع } & \multicolumn{6}{|c|}{ سنوات المجلتين المدروستتين } & \multirow{3}{*}{ المشاركة } & \multirow[t]{3}{*}{ أسم المجلة } \\
\hline & & \multicolumn{2}{|c|}{2013} & \multicolumn{2}{|c|}{2012} & \multicolumn{2}{|c|}{2011} & & \\
\hline$\%$ & العدد & $\%$ & العدد & $\%$ & العدد & $\%$ & العدد & & \\
\hline 33.3 & 3 & 50.0 & 1 & 0 & 0 & 28.6 & 2 & فردي & \multirow{4}{*}{ المجلة العلمية } \\
\hline 44.4 & 4 & 0.0 & 0 & 0 & 0 & 57.1 & 4 & زوجي & \\
\hline 11.1 & 1 & 50.0 & 1 & 0 & 0 & 0.0 & 0 & ثلاثي & \\
\hline 11.1 & 1 & 0.0 & 0 & 0 & 0 & 14.3 & 1 & رباعي & \\
\hline 100.0 & 9 & 100.0 & 2 & $\mathbf{0}$ & $\mathbf{0}$ & 100.0 & 7 & & المجموع \\
\hline 53.8 & 14 & 44.4 & 4 & 46.2 & 6 & 100.0 & 4 & فردي & \multirow{4}{*}{ للبحوث الزراعية المصرية } \\
\hline 23.1 & 6 & 44.4 & 4 & 15.4 & 2 & 0.0 & 0 & زوجي & \\
\hline 23.1 & 6 & 14.3 & 1 & 38.5 & 5 & 0.0 & 0 & ثلاثي & \\
\hline 0.0 & 0 & 0.0 & 0 & 0.0 & 0 & 0.0 & 0 & رباعي & \\
\hline 100.0 & 26 & 100.0 & 9 & 100.0 & 13 & 100.0 & 4 & & المجموع \\
\hline
\end{tabular}

بحثا بنسبة 84.6\% من إجمالي بحوث العلوم الاجتماعية مقارنة

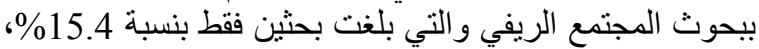

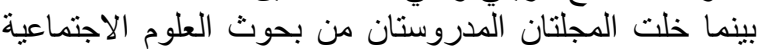

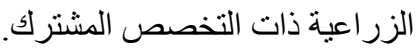

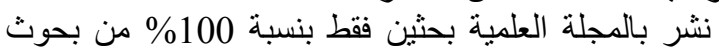

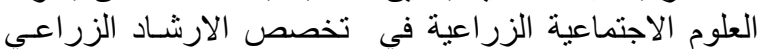

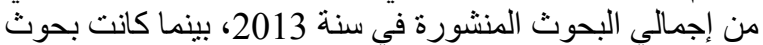
المجتمع الريفي المنشورة في المجلة المصرية للبحوث الزئة الزر اعية

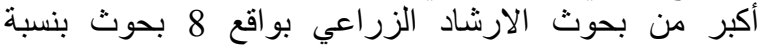

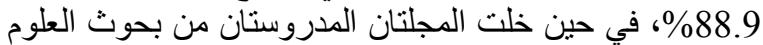

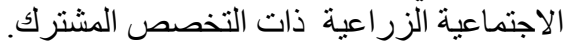

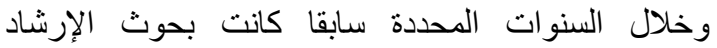

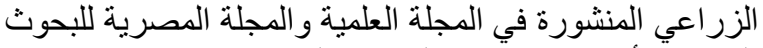

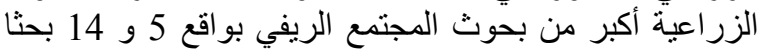

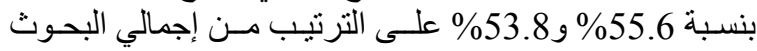

لم تنشر أي بحوث للعلوم الاجتماعية الزراعية في المجلة

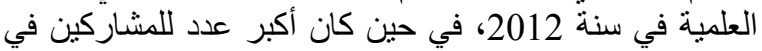

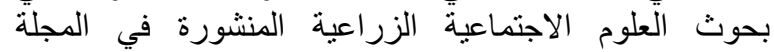

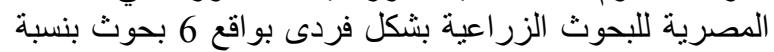

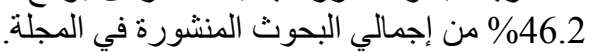

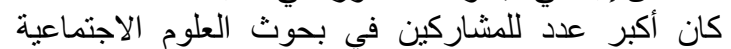

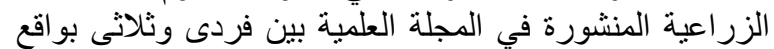

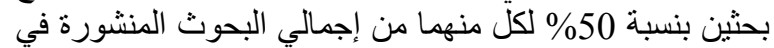

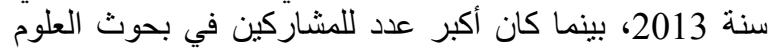

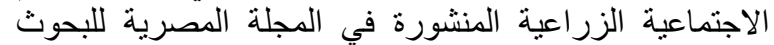
الزر اعية بين فردى وزوجى بواعق 4 بحوث بنسبة فئة 44.4\% لكل

$$
\text { منهما. }
$$

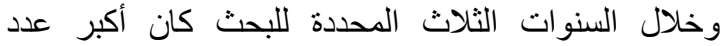

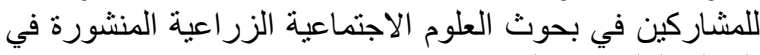
المجلة العلمية بشكل زوجى بو اقع 4 بحوث بنسبة 44.4\% من اعن اعنة 
جدول (4): مقارنة بين المشاركين في بحوث العلوم الاجتماعية الزراعية المنثورة بالمجلتين الددروستين من حيث تخصصاتهم العلمية.

\begin{tabular}{|c|c|c|c|c|c|c|c|c|c|}
\hline \multicolumn{2}{|c|}{ 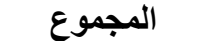 } & \multicolumn{6}{|c|}{ سنوات المجلتين المدروستين } & \multirow{3}{*}{ التخصص } & \multirow[t]{3}{*}{ أسم المجلة } \\
\hline & & \multicolumn{2}{|c|}{2013} & \multicolumn{2}{|c|}{2012} & \multicolumn{2}{|c|}{2011} & & \\
\hline$\%$ & العدد & $\%$ & العدد & $\%$ & العدد & $\%$ & العدد & & \\
\hline 55.6 & 5 & 100.0 & 2 & $\mathbf{0}$ & $\mathbf{0}$ & 42.9 & 3 & ارششاد زراعي & ت \\
\hline 44.4 & 4 & 0.0 & $\mathbf{0}$ & $\mathbf{0}$ & $\mathbf{0}$ & 57.1 & 4 & مجتمع ريفي & الناعلهة العلمية لكليه \\
\hline 0.0 & $\mathbf{0}$ & $\mathbf{0 . 0}$ & $\mathbf{0}$ & $\mathbf{0}$ & $\mathbf{0}$ & 0.0 & $\mathbf{0}$ & مشترك - مشك & \\
\hline 100.0 & 9 & 100.0 & 2 & $\mathbf{0}$ & $\mathbf{0}$ & 100.0 & 7 & & المجموع \\
\hline 53.8 & 14 & 11.1 & 1 & 84.6 & 11 & $\mathbf{5 0 . 0}$ & 2 & ارشاد زراعي & \\
\hline 46.2 & 12 & 88.9 & 8 & 15.4 & 2 & 50.0 & 2 & مجتمع ريفي & عية لمركز \\
\hline 0.0 & $\mathbf{0}$ & 0.0 & $\mathbf{0}$ & $\mathbf{0 . 0}$ & $\mathbf{0}$ & 0.0 & $\mathbf{0}$ & مشترك & \\
\hline 100.0 & 26 & 100.0 & 9 & 100.0 & 13 & 100.0 & 4 & & 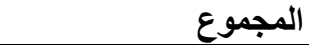 \\
\hline
\end{tabular}

الزراعية المنشورة في المجلة المصرية للبحوث الزراعية

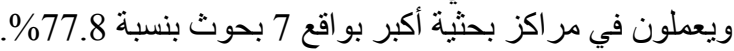

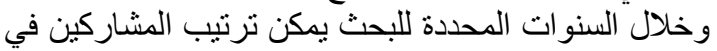

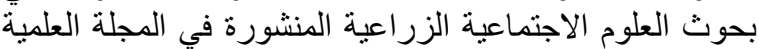

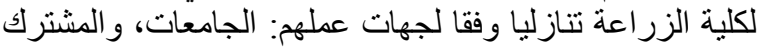

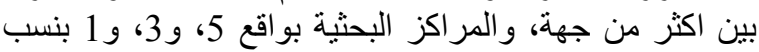

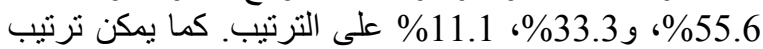

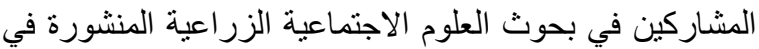

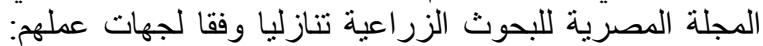

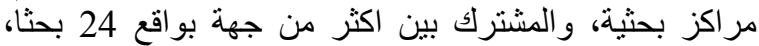

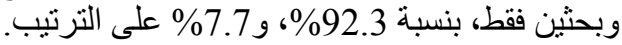

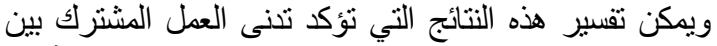
الباحثين على مستوى المنظمات العلمية المحلية إلى افتقار آليات ومحفزات العمل بروح الفريق العلمى بين المؤسسات والمنظمات المئن

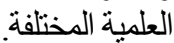

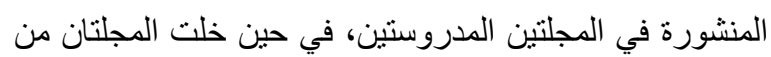

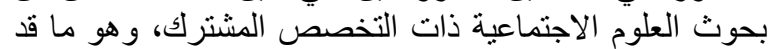

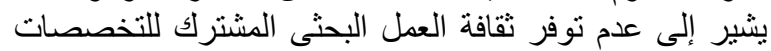
العلمية المختلفة لاى الباحثين أساسا.

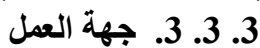

أظهرت النتائج في جدول العيد (5) أن المشاركين في بحوث

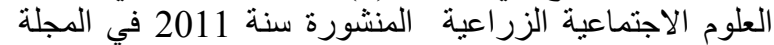
العلمية كانت جهات عملهم في الجامعات واعثة والمشترك بئ بين أكثر

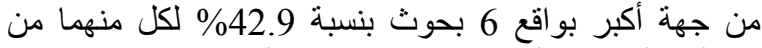

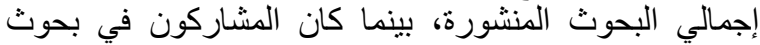

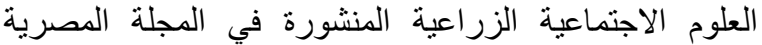
للبحوث الزر اعية أكبر، يعملون بالمر اكز البحثية بواقع 4 بحوث

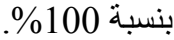

جدول (5): مقارنة بين المشاركين في بحوث العلوم الاجتماعية الزراعية المنشورة بالمجلتين المدروستين من حيث جهات عملهم.

\begin{tabular}{|c|c|c|c|c|c|c|c|c|c|}
\hline \multicolumn{2}{|c|}{ المجموع } & \multicolumn{6}{|c|}{ سنوات المجلتين المدروستين } & \multirow{3}{*}{ جهة العمل } & \multirow[t]{3}{*}{ أسم المجلة } \\
\hline & & \multicolumn{2}{|c|}{2013} & \multicolumn{2}{|c|}{2012} & \multicolumn{2}{|c|}{2011} & & \\
\hline$\%$ & العدد & $\%$ & العدد & $\%$ & العدد & $\%$ & العدد & & \\
\hline 55.6 & 5 & 100.0 & 2 & 0 & 0 & 42.9 & 3 & جامعات & \\
\hline 11.1 & 1 & 0.0 & 0 & 0 & 0 & 14.3 & 1 & مراكز بحثية & المجلة العلمية \\
\hline 33.3 & 3 & 0.0 & 0 & 0 & 0 & 42.9 & 3 & مشترك & \\
\hline 100.0 & 9 & 100.0 & 2 & 0 & 0 & 100.0 & 7 & & المجموع \\
\hline 0.0 & 0 & 0.0 & 0 & 0.0 & 0 & 0.0 & 0 & جامعات & \\
\hline 92.3 & 24 & 77.8 & 7 & 100.0 & 13 & 100.0 & 4 & مراكز بحثية & المجلثة المصري \\
\hline 7.7 & 2 & 22.2 & 2 & 0.0 & 0 & 0.0 & 0 & مشترك & \\
\hline 100.0 & 26 & 100.0 & 9 & 100.0 & 13 & 100.0 & 4 & & 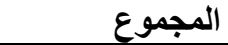 \\
\hline
\end{tabular}

3.3.3. 4. المشاركة المحلية والإقليمية والدولية

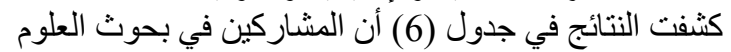
الاجتماعية الزراعية المنشورة سنة 2011 في ألمجلة العلمية،

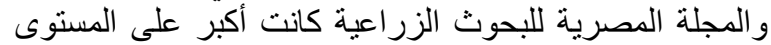
المحلى بو اقع 5 و4 بحوث لإثلى بنسبة 71.4\% و100\% الترتيب من إجمالى البحوث المن المنشورة. ولم تنشر أي بحوث للعلوم الاجنماعية الزراعية في في المجلة

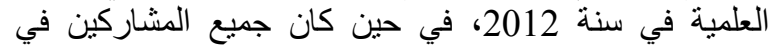
بحوث العلوم الاجتماعية الزراعية المنشورة في المجلة

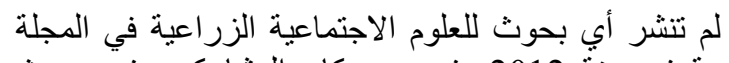

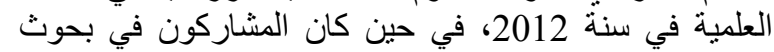
العلوم الاجتماعية الزراعية المنشورة في الزئية المجلة ألمصرية للبحوث الزر اعية ويعملون في مر اكز بحثية أكبر بو اقع الئع 13 بحثا

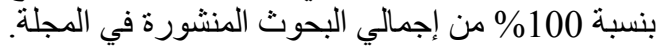
وكان المشاركون في بحوث العية العلوم الاجتماعية الزراعية فئية

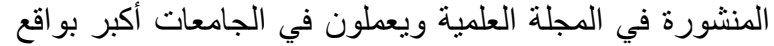

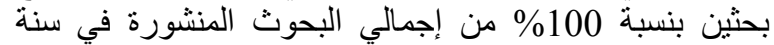
2013، بينما كان المشاركون في بحوث العلوم الاجتماعية 
جدول (6): مقارنة بين المشاركين في بحوث العلوم الاجتماعية الزراعية، المنشورة بالمجتين المدروستين من حيث المشاركة المحلية والاقليمية والاولية.

\begin{tabular}{|c|c|c|c|c|c|c|c|c|c|}
\hline \multicolumn{2}{|c|}{ المجموع } & \multicolumn{6}{|c|}{ سنوات المجلتين المدروستين } & \multirow{3}{*}{ المشاركة } & \multirow[t]{3}{*}{ أسم المجلة } \\
\hline & & \multicolumn{2}{|c|}{2013} & \multicolumn{2}{|c|}{2012} & \multicolumn{2}{|c|}{2011} & & \\
\hline$\%$ & العدد & $\%$ & العدد & $\%$ & العدد & $\%$ & العدد & & \\
\hline 55.6 & 5 & 0.0 & 0 & 0 & 0 & 71.4 & 5 & مصر & \\
\hline 33.3 & 3 & 100.0 & 2 & 0 & 0 & 14.3 & 1 & ل دول عربية & \\
\hline 11.1 & 1 & 0.0 & 0 & 0 & 0 & 14.3 & 1 & دول اجنبية & المجله العقلمي \\
\hline 0.0 & 0 & 0.0 & 0 & 0 & 0 & 0.0 & 0 & مشترك & \\
\hline 100.0 & 9 & 100.0 & 2 & 0 & 0 & 100.0 & 7 & & المجموع \\
\hline 100.0 & 26 & 100.0 & 9 & 100.0 & 13 & 100.0 & 4 & مصر | مل مبر & \\
\hline 0.0 & 0 & & 0 & 0.0 & 0 & 0.0 & 0 & دول عربية & المحلة المصير بة \\
\hline 0.0 & 0 & 0.0 & 0 & 0.0 & 0 & 0.0 & 0 & دول اجنبية & للانبوث \\
\hline 0.0 & 0 & 0.0 & 0 & 0.0 & 0 & 0.0 & 0 & مشترك - مشت & \\
\hline 100.0 & 26 & 100.0 & 9 & 100.0 & 13 & 100.0 & 4 & & المجموع \\
\hline
\end{tabular}

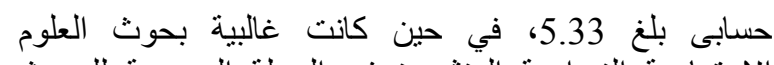

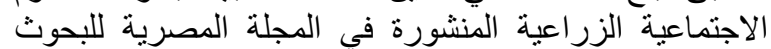

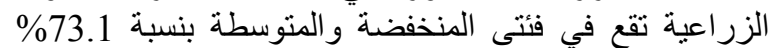

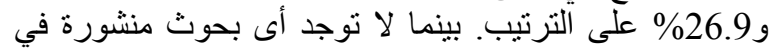
فئة المشاركة المرتفعة لكلتا المجلتين المدروستين.

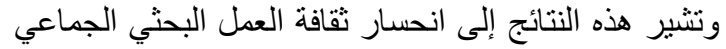

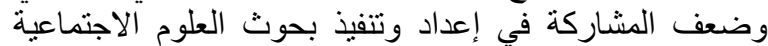

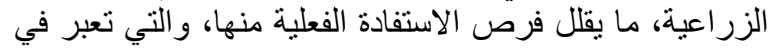
كثير منها عن واقع مخالف للبيئة الاجتماعية الريفية الحقية الحقيقية لافتقار ها للرؤية المتكاملة، و اتباع نهج المعالجة الأحادية للقضاياي التحية المختلفة.

3. 4. معنوية الفروق في درجة المشاركة الإجمالية لبحوث المثرث

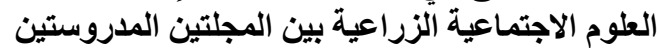

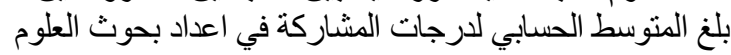

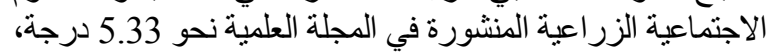
في حين بلغ 4.76 درجة لبحوث العيت العلوم الاجتماعية الزراعية

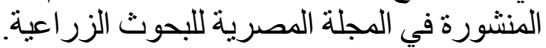

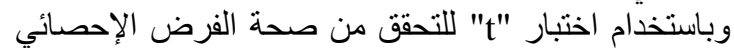

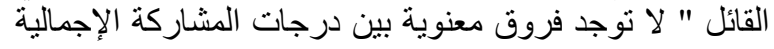

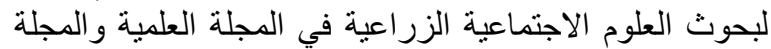

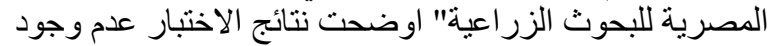

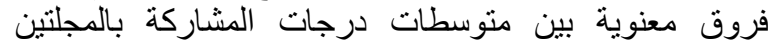

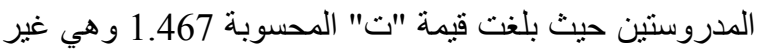
معنوية، بالتالي لا يمكن رفض الفرض الفر الإحصائي.
المصرية للبحوث الزراعية على المستوى المحلى بواقع 13

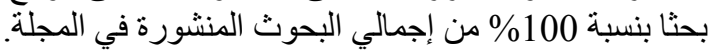

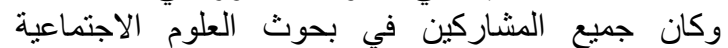

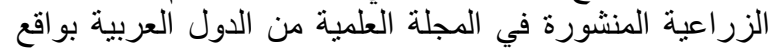
بحثين بنسبة 100\% من إجمالي البحوث في سنة العنة 2013، بينما كان جميع المشاركين في بحوث الجمالي العلوم الاجتماعية الزراعية

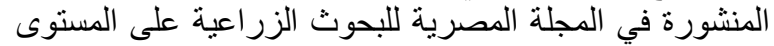

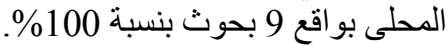

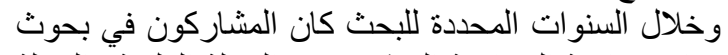

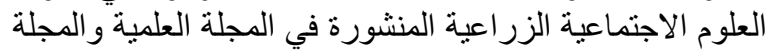

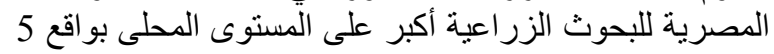

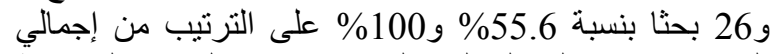

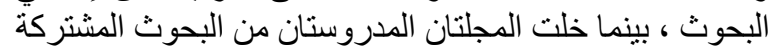

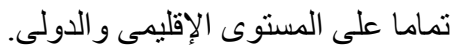
وتثبير هذه النتائج إلى النخفاض المشالى المشاركة المحلية والإقليمية

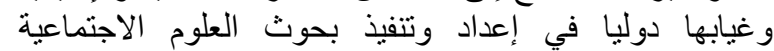

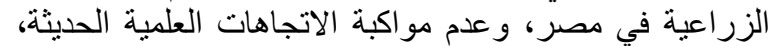

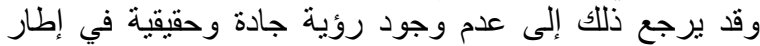

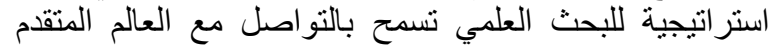
للاستفادة منها ونقل خبر اته المنو افقة مع البيئة المحلية. 3. 3. 5. مستوى المشاركة الإجمالية في إعداد البحوث البحث

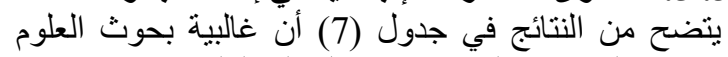
الاجتماعية الزراعية المنشورة في المجلة العلمية تقع في فئتي

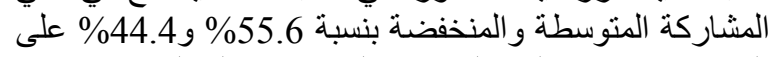
الترتيب من إجمالى البحوث المنشورة بالمجلة، وبمنوسط

جدول (7): مقارنة بين مستوى المشاركة الإجمالية لبحوث العلوم الاجتماعية الزراعية في المجلتين المدروستين.

\begin{tabular}{|c|c|c|c|c|}
\hline \multicolumn{4}{|c|}{ الابحاث } & \multirow{3}{*}{ العدد } \\
\hline \multicolumn{2}{|c|}{ عن مزكز البحوثية الزيادرة } & \multicolumn{2}{|c|}{ المجلة العلمية لكلية الزراعة } & \\
\hline$\%$ & العدد & $\%$ & 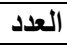 & \\
\hline 73.1 & 19 & 44.4 & 4 & منخفض (4 - 5) \\
\hline 26.9 & 7 & 55.6 & 5 & متوسط (6 - 8) \\
\hline $\mathbf{0}$ & $\mathbf{0}$ & $\mathbf{0}$ & $\mathbf{0}$ & مرتفع (9 - 10) \\
\hline 26 & 26 & 100.0 & 9 & المجموع \\
\hline
\end{tabular}




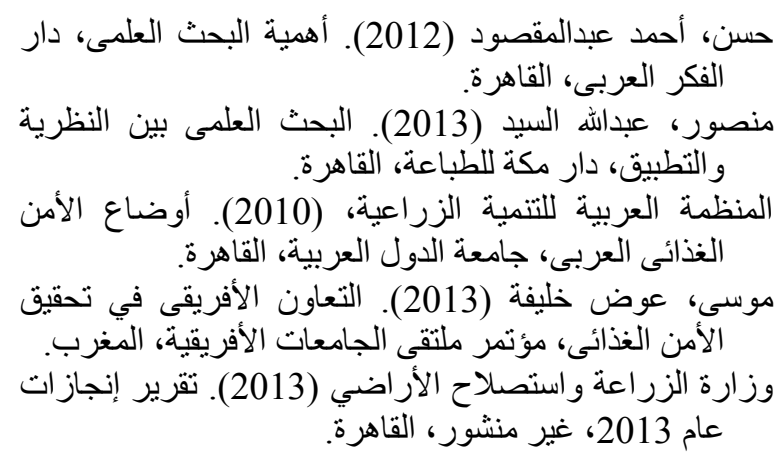

\section{REFERENCES}

Committee on Facilitating Interdisciplinary Research (CFIR), Committee on Science, Engineering, and Public Policy (CSEPP) (2004). Facilitating interdisciplinary research. The National Academies of science. Press Washington, D.C. Website: www.nap.edu

Millar M. M. and Dillman D. A. (2010). Defining and identifying interdisciplinary research among doctoral candidates, social and economic sciences research center, Washington state university. Website: http://www.sesrc.wsu.edu/dillman/papers/201 0/Millar\%20\%20Dillman\%20IDR\%20Cognit ive\%20Interview\%20Tech\%20Report\%20fin al.pdf

Repko A. F. (2012). Interdisciplinary Research. Process and Theory. Second Edition, SAGE

Publications, Inc. Website:

http://www.sagepub.com/upmdata/43242 1.pdf

The National Science Foundation (NSF), (2014) Virginia,USA,

http://www.nsf.gov/od/iia/additional resourc es/interdisciplinary research/index.jsp

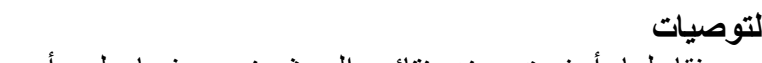

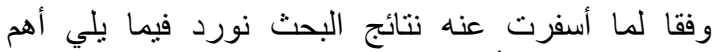

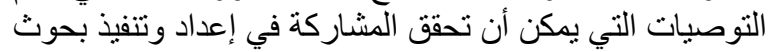

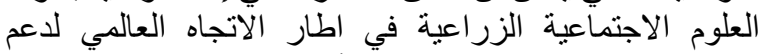

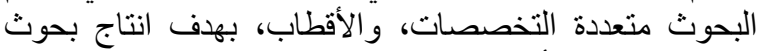

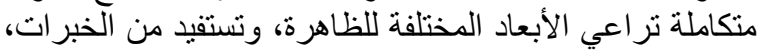
و الثقافات المختلفة:

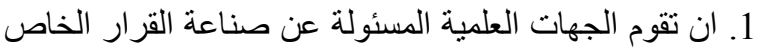

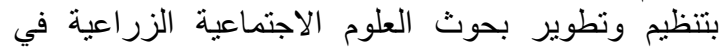

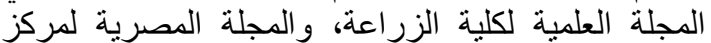

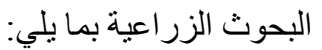

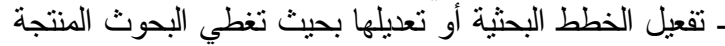

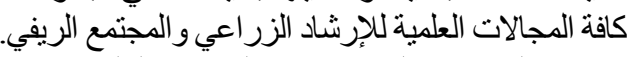

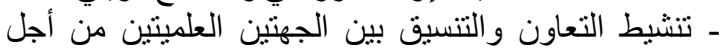

انتاج بحوث مشتركة بينهما تضم أكبر عدد من التين الباحثين،

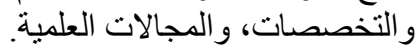

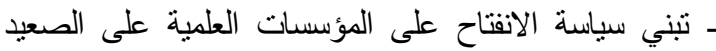

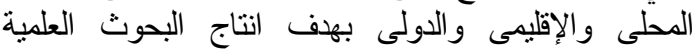

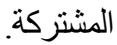

2. ان تقوم اللجان العلمية الدائمة لترقية باحثي العلوم الاجتماعية

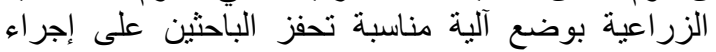

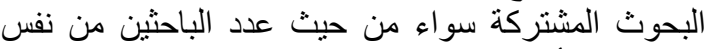
التخصص، أو من تخصصنات مختلفة.

\section{4. - أمراجع}

إسماعيل، سعيد (2010). قو اعد أساسية في البحث العلمى، الطبعة الثانية، المدينة المنورة، السعودية.

بدير، أسامة (2014). دور العلوم الاجتماعية الزر اعية في تبنى العئي

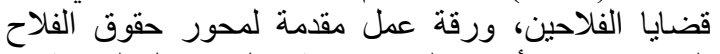

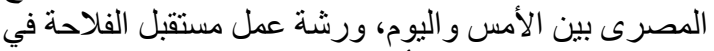

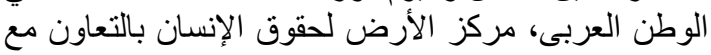
الثبكة اللبنانية للتنمية، لبنان.

برنامج تمبوس (2010). المرحلة الر ابعة 2007 - 2013، نبذة اللبنة مختصرة عن البرنامج، المفوضية الاوربية.

Website:http://eacea.ec.europa.eu/tempus/tools/d ocuments/brochure_2010/brochure_ar.pdf بوبر، كارل (2009). منطق البحث العلمى، ترجمة محمد البغدادى، الطبعة الاولى، مركز دراسات الوحدة العربية، القاهرة. 